\title{
COMPARATIVO DE INDICADORES DE MANUTENÇÕES: UM ESTUDO DE CASO REALIZADO EM BOMBAS DE POLPA *
}

\author{
Izabel Cristina de Freitas Souza ${ }^{1}$ \\ Luciano José Vieira Franco ${ }^{2}$ \\ Jussara Fernandes Leit ${ }^{2}$ \\ Fernanda Maciel Zeferino ${ }^{2}$ \\ Alexandre Magno Franco Ferreira ${ }^{2}$ \\ Márcio Roberto Rodrigues ${ }^{2}$ \\ Mauricio Vieira ${ }^{2}$ \\ Nilo Antunes Ferreira ${ }^{2}$
}

\section{Resumo}

O presente estudo teve por objetivo verificar qual tipo de manutenção é o mais indicado aos equipamentos bombas de polpa de uma usina de beneficiamento de minério de ferro. Este é um estudo de caso de natureza documental, exploratória e explicativa. No desenvolvimento desse estudo foi realizada a análise dos indicadores de disponibilidade física (DF), horas em operação, número de falhas, tempo médio entre falhas (MTBF), tempo gastos para reparo (MTTR) e custo das bombas de polpas com manutenções corretivas e preventivas. Foram coletados dados referentes ao período de janeiro a setembro de 2016. Após análise dos dados, a pesquisa identificou que as manutenções corretivas apresentaram melhores índices de DF e MTTR, e quanto às manutenções preventivas, atingiram melhores resultados em horas em operação, número de falhas, MTBF e custo. Por fim concluiu-se que manutenção preventiva, no geral, mostrou-se viável, pois apresentou melhor desempenho na maioria dos indicadores analisados.

Palavras-chave: Manutenção Preventiva. Manutenção Corretiva. Bombas de Polpa.

\section{COMPARISON OF MAINTENANCE INDICATORS: A CASE STUDY CARRIED} OUT ON PULP PUMPS

\begin{abstract}
The present study had as objective to verify which type of maintenance is most appropriate to the equipment pulp pumps of an iron mineral beneficiation. This is a case study of documentary nature, exploratory and explanatory. In the development of this study, the analysis of the physical availability indicators (DF), hours in operation, number of failures, average time between failures (MTBF), time spent to repair (MTTR) and cost of pulp pumps with corrective maintenance were performed. Preventive measures. Data were collected from January to September of 2016. After analysis, the research identified that corrective maintenance had better DF and MTTR, indexes and preventive maintenance achieved better results in hours in operation, number of failures, MTBF And cost. Finally it was concluded that preventive maintenance, in general, proved feasible, since it presented better performance in most of the indicators analyzed.
\end{abstract}

Keywords: Preventive Maintenance. Corrective Maintenance. Pulp Pumps.

1 Graduando em Engenharia de Produção, Fundação Presidente Antônio Carlos, Barão de Cocais, Minas Gerais, Brasil.

2 Engenheiro, Professor da Fundação Presidente Antônio Carlos, Conselheiro Lafaiete, Minas Gerais, Brasil. 


\section{INTRODUÇÃO}

Em meio à crise instalada no Brasil no ano de 2014, as empresas do setor de mineração de minério de ferro foram atingidas pela queda do preço e da demanda de produtos vendidos para a China, país que mais compra esse produto no mundo. Segundo o Ministério do Desenvolvimento, Indústria e Comércio (MDIC) apud Francia $^{1}$, a China comprou 47,3\% a menos de minério em 2015 se comparado com o mesmo período em 2014. Com a diminuição da demanda, houve uma crescente oferta do produto no cenário mundial, fazendo com que o preço da tonelada do minério começasse a despencar, passando de US\$140,00/ton. em janeiro de 2014, para pouco mais de US\$50,00/ton. em janeiro de 2016.

Neste cenário, as mineradoras de minério de ferro buscaram realizar melhorias no processo produtivo para reduzir os custos e aumentar a produtividade. Desta forma, esta análise deve ser realizada para identificar desvios e aspectos que possam ser melhorados.

Um dos problemas encontrados no beneficiamento de minério de ferro da mineradora deste estudo é o alto número de manutenções realizadas no equipamento bomba de polpa. Sendo assim, esta pesquisa busca melhorias na produtividade deste equipamento. Para isto, inicialmente é necessário entender o que é a bomba de polpa e qual sua função.

Rocha ${ }^{2}$ informa que o bombeamento de polpa é um dos meios mais simples, econômico e rápido para se transportar sólidos que é utilizado em plantas de beneficiamento mineral, onde polpas de minério são bombeadas entre os processos de concentração.

Silva $^{3}$ esclarece que bombas centrífugas de polpa são amplamente utilizadas em processos industriais, incluindo as plantas de mineração, quando o arranjo mecânico não permite o transporte da polpa por gravidade, ou quando há necessidade de uma pressão residual predeterminada. Para melhor 0 entendimento, a Figura 1 apresenta uma bomba de polpa utilizada no processo de beneficiamento de minério de ferro.

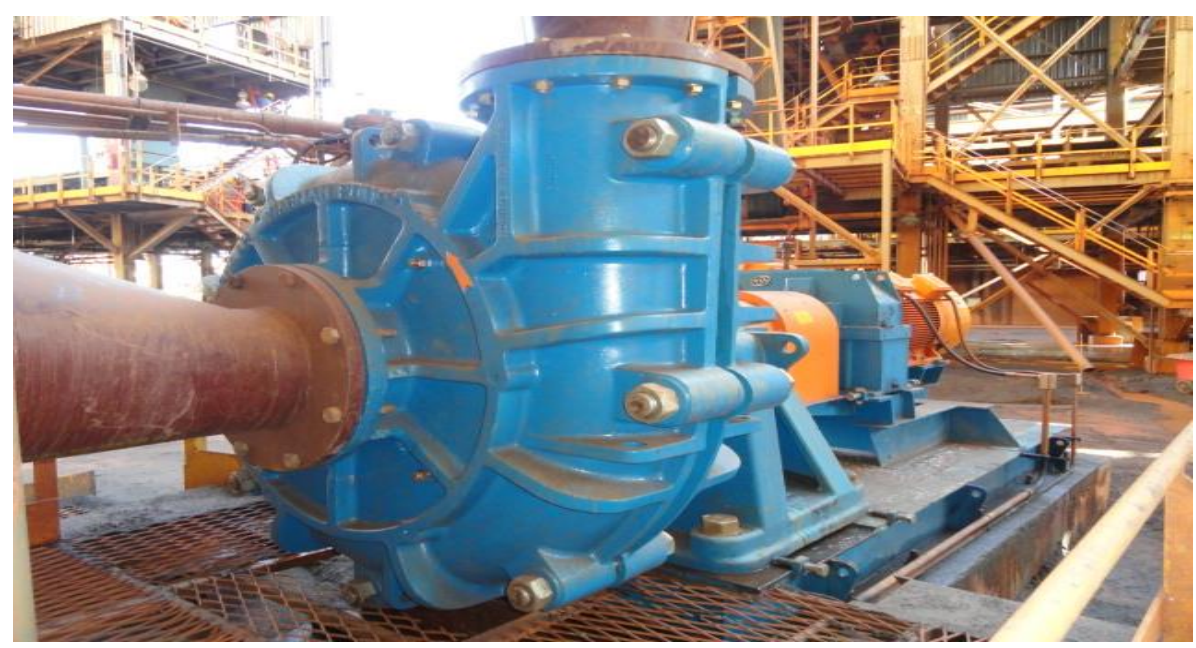

Figura 1 - Bomba de Polpa (Pesquisa direta, 2016).

A bomba de polpa, como ilustrada na Figura 1, é constituída de uma carcaça estacionária, possuindo internamente um rotor montado sobre um eixo rotativo. Suas manutenções interferem na disponibilidade do equipamento, o que afeta a 
capacidade de produção do beneficiamento de minério de ferro. Em consequência, o custo do produto é afetado.

Kardec et $\mathrm{al}^{4}$ ressaltam a importância da manutenção como função estratégica para melhoria dos resultados do negócio e aumento da competitividade das organizações. Sendo assim, a manutenção como uma das atividades fundamentais do processo produtivo, deve ser um agente proativo. O objetivo de um processo de manutenção relaciona-se à garantia de que equipamentos e instalações estejam disponíveis para atender a um processo de produção e execução de um determinado serviço com padrão de qualidade, segurança, confiabilidade, preservação ambiental e custos adequados. Assim, toda organização produtiva deve executar a manutenção como uma forma de garantir a continuidade de produção, evitando gastos desnecessários e perda da qualidade do produto.

Nessa abordagem, Santana et $a^{5}{ }^{5}$ definem o termo manutenção como sendo o conjunto de ações para a conservação e permanência de algo em uma determinada situação, podendo o termo ser entendido ainda como o conjunto de cuidados necessários para que máquinas e motores possam funcionar de forma regular e contínua. Assim, o propósito de todo processo de manutenção é "evitar a degradação natural das máquinas e equipamentos".

Dentre os vários tipos de manutenção, a corretiva e a preventiva, são as mais executadas pelas empresas. Sobre a manutenção corretiva, Kardec et $\mathrm{al}^{4}$ destacam a busca por correção ou restauração das condições de funcionamento do equipamento ou sistema, existindo duas condições específicas: desempenho deficiente e ocorrência de falha.

$\mathrm{Na}$ mesma linha de raciocínio, Oliveira ${ }^{6}$ salienta que a manutenção corretiva é a intervenção imediata no equipamento e faz-se necessária para que se evitem danos aos instrumentos e equipamentos, bem como à integridade do operário e danos ao meio ambiente.

Em relação à manutenção preventiva, Santana et $\mathrm{al}^{5}$ afirmam que essa constituiu-se como um processo caracterizado pela elaboração de um plano de manutenção, de forma a garantir a integridade dos equipamentos e maquinário, efetuando-se a troca, antes que ocorra a paralisação das atividades produtivas.

Kach et $\mathrm{al}^{7}$ concordam com as ideias apresentadas anteriormente, mencionando que a manutenção preventiva é um procedimento aplicado como forma de se evitar paradas das máquinas. Nessa abordagem, Oliveira ${ }^{6}$ comenta que a manutenção preventiva objetiva a prevenção de falhas ou paradas do equipamento por quebras, procurando-se também dar apoio à manutenção corretiva pela aplicação de uma metodologia de trabalho periódico.

Entretanto para realizar o controle das manutenções é necessário medir e realizar o acompanhamento destas, que pode ser realizado por meio de indicadores, que segundo Branco Filho $(2006)^{8}$, são dados estatísticos relativos a um ou diversos processos de manutenção que devem ser controlados. Esse autor ainda complementa que servem para medir o desempenho contra metas e padrões estabelecidos.

Como indicadores, encontram-se a disponibilidade do equipamento, o tempo médio entre falhas (TMEF ou MTBF), o tempo médio para reparo (TMPR ou MTTR), custos de manutenção, entre outros. Segundo Filho $^{8}$, a disponibilidade serve para indicar a probabilidade de uma máquina estar disponível para produção. De acordo com Netto $^{9}$, o tempo médio para reparo trata-se de um indicador que representa o tempo médio entre a ocorrência de uma falha e a próxima, ou ainda o tempo de funcionamento da máquina ou equipamento diante das necessidades de produção 
até a próxima falha. Sobre o tempo médio para reparo, (Zen, 2008, apud Netto $^{9}$ ) informa que esse indicador aponta o tempo que a equipe de manutenção demanda para reparar e disponibilizar a máquina ou equipamento para o sistema produtivo. Por fim, este autor afirma que o custo de manutenção é um dos principais indicadores e representa a somatória básica das seguintes parcelas: custos de intervenção de manutenção (recursos materiais, sobressalentes e mão de obra), custos próprios (internos) da equipe de manutenção, tais como administração, treinamento, dentre outros, os custos de perdas de produção (se houver), e o custo da perda de oportunidade pela falta do produto se houver demanda.

A partir do exposto, nota-se que a manutenção exerce papel essencial na confiabilidade dos equipamentos. Filho ${ }^{8}$ conceitua confiabilidade como a probabilidade do evento falha não ocorrer. Consoante com Kardec et $\mathrm{al}^{4}$, confiabilidade é a capacidade de um item desempenhar uma função requerida sob condições específicas, durante um intervalo de tempo.

Dentro deste contexto, a pesquisa tem como objetivo verificar qual tipo de manutenção é o mais indicado para manutenção do processo de bomba de polpa.

\section{MATERIAIS E MÉTODOS}

Este artigo é um estudo caso com natureza de pesquisa documental, exploratória, finalidade de proporcionar maior familiaridade ao autor com as bombas de polpa; e explicativa, visando identificar variáveis que determinam a razão e ocorrência de um fenômeno, investigando relações de causa efeito.

O trabalho foi desenvolvido em uma usina de beneficiamento de minério de ferro de uma empresa mineradora situada na Região do Médio Piracicaba em Minas Gerais. A pesquisa foi direcionada para os equipamentos de bombas de polpa e foi realizada no período de outubro a dezembro de 2016.

$O$ universo da pesquisa foi de 30 bombas de polpa, selecionadas do setor de concentração magnética da usina, sendo estudados $50 \%$ dos equipamentos. A escolha da amostra deu-se pelo método de acessibilidade, uma técnica não probabilística, uma vez que um dos autores da pesquisa trabalha na área onde se encontram os equipamentos e tem acesso aos documentos e relatórios do processo de manutenção.

No desenvolvimento desse estudo foi realizada a análise dos indicadores de disponibilidade física (DF), horas em operação, número de falhas, tempo médio entre falhas (MTBF), tempos gastos para reparo (MTTR) e custo das bombas de polpas com manutenções corretivas e preventivas. Esses dados possuem natureza quantitativa, foram apresentados e analisados por meio de tabelas e gráficos.

Assim, os indicadores das manutenções corretivas e preventivas foram analisados com o objetivo de verificar qual tipo de manutenção é o mais indicado para as bombas de polpa da usina de beneficiamento de minério de ferro.

Por meio de indicadores do desempenho de manutenção, o presente trabalho visou fazer um comparativo entre cada estratégia de manutenção adotada pela empresa. Foram coletados dados referentes ao período de janeiro a setembro de 2016.

\section{RESULTADOS E DISCUSSÃO}

A manutenção em bombas de polpa tem como objetivo garantir a eficiência do equipamento, aumentando sua disponibilidade física no processo produtivo. Para realização desta manutenção, este trabalho adotou uma estratégia que leva em 
consideração o grau de criticidade dos equipamentos, que é definido conforme a existência de equipamentos reservas. A Tabela 1 apresenta o grau de criticidade das bombas de polpas estudadas.

Tabela 1 - Criticidade de Equipamentos.

\begin{tabular}{|c|c|c|c|c|}
\hline LINHA & QT & $\begin{array}{c}\text { LINHA / BOMBA DE } \\
\text { POLPA }\end{array}$ & CRITICIDADE (\%) & $\begin{array}{c}\text { GRAU DE } \\
\text { CRITICIDADE }\end{array}$ \\
\hline \multirow{5}{*}{ Linha Simples } & 1 & Linha 1 - BP 1101 & $33,5 \%$ & Médio \\
\hline & 2 & Linha 2 - BP 1307 & $33,5 \%$ & Médio \\
\hline & 3 & Linha 3 - BP 1804 & $33,5 \%$ & Médio \\
\hline & 4 & Linha 4 - BP 2307 & $33,5 \%$ & Médio \\
\hline & 5 & Linha 5 - BP 1305 & $33,5 \%$ & Médio \\
\hline \multirow{10}{*}{$\begin{array}{l}\text { Linha com } \\
\text { Reserva }\end{array}$} & 6 & Linha 6 - BP 1304 & $9,6 \%$ & Baixo \\
\hline & 7 & Linha 6 - BP 1304R & $9,6 \%$ & Baixo \\
\hline & 8 & Linha 7 - BP 2304 & $9,6 \%$ & Baixo \\
\hline & 9 & Linha 7 - BP 2304R & $9,6 \%$ & Baixo \\
\hline & 10 & Linha 8 - BP 3304 & $9,6 \%$ & Baixo \\
\hline & 11 & Linha 8 - BP 3304R & $9,6 \%$ & Baixo \\
\hline & 12 & Linha 9 - BP 2308 & $9,6 \%$ & Baixo \\
\hline & 13 & Linha 9 - BP 2308R & $9,6 \%$ & Baixo \\
\hline & 14 & Linha 10 - BP 4308 & $9,6 \%$ & Baixo \\
\hline & 15 & Linha 10 - BP 4308R & $9,6 \%$ & Baixo \\
\hline
\end{tabular}

Como mostrado na Tabela 1, as linhas simples (1-5) possuem cinco bombas de polpa com grau de criticidade médio, representando $33,3 \%$ da amostra; e as linhas com reservas (6-15) possuem 10 equipamentos, com grau de criticidade baixo, representando $66,7 \%$ da amostra.

A empresa adota a manutenção preventiva para as bombas de polpas com grau de criticidade médio. Essas manutenções ocorrem em paradas programadas da usina, sendo: uma parada geral da usina (PGU) e duas paradas de linha $(P L)$ por mês.

Para as linhas que tem bombas de polpa com grau de criticidade baixo, adota-se a manutenção corretiva. As intervenções nessas linhas ocorrem mediante a falha ou por solicitação da manutenção preditiva ou inspeção sensitiva.

\subsection{Manutenção preventiva em bombas de polpa}

Para gerar o plano de manutenção preventiva das bombas de polpa, consideram-se os relatórios das manutenções preditivas e das inspeções sensitivas além da vida útil dos componentes. Após a equipe de manutenção e planejamento analisar esses documentos, definiu-se quais atividades foram realizadas e também quais bombas de polpas foram priorizadas. Em sequência, foi gerada uma ordem de manutenção contendo todos os recursos necessários e a descrição de todas as atividades que foram executadas no plano de manutenção preventiva. Em média, a periodicidade das intervenções preventiva nas bombas de polpas é quinzenal.

Destaca-se ainda que as manutenções preventivas realizadas nas bombas de polpa consistem em efetuar inspeções nos componentes quanto ao seu desgaste. Isso para substituí-los, quando danificados ou no fim de sua vida útil.

\subsection{Manutenção corretiva em bombas de polpa}

A manutenção corretiva em bombas de polpa consiste em efetuar reparos no equipamento mediante a falha ou solicitação de intervenção da manutenção preditiva ou inspeção sensitiva. 
A partir da solicitação de intervenção, a equipe de manutenção corretiva verifica quais são os recursos necessários para corrigir a falha na bomba de polpa. Identificando, estes recursos são requisitados ao setor de almoxarifado para que a troca das peças seja efetuada. Posterior à correção da falha, é gerada uma ordem de manutenção para descrever quais atividades foram realizadas e também para apropriar todos os recursos que foram utilizados na intervenção corretiva.

\subsection{Análise dos dados coletados}

As bombas de polpa situam-se em linhas simples e/ou com reserva. As de linha simples são aquelas que não possuem bomba de polpa em estoque, para realizar a troca; e a linha com reserva são aquelas que possuem equipamentos reservas apresentam criticidade baixa, pois em caso de falha do equipamento principal é acionado automaticamente o equipamento reserva que está em stand-by, portando a falha não acarreta paralisação do processo produtivo. São os equipamentos das linhas $6,7,8,9,10 . "$

Uma das atividades realizadas no setor de manutenção foi o acompanhamento da disponibilidade física destas bombas de polpa, no período de janeiro a setembro de 2016, podendo ser verificadas na Tabela 2.

Tabela 2 - Disponibilidade Física (DF).

\begin{tabular}{c|c|c|c}
\hline \multirow{3}{*}{ LINHA } & QT & $\begin{array}{c}\text { LINHA / BOMBA DE } \\
\text { POLPA }\end{array}$ & $\begin{array}{c}\text { DISPONIBILIDADE } \\
\text { FíSICA - DF (\%) }\end{array}$ \\
\hline \multirow{4}{*}{ Linha Simples } & 1 & Linha 1 - BP 1101 & 98,12 \\
\cline { 2 - 4 } & 2 & Linha 2 - BP 1307 & 99,84 \\
\cline { 2 - 4 } & 3 & Linha 3 - BP 1804 & 96,02 \\
\cline { 2 - 4 } & 4 & Linha 4 - BP 2307 & 87,87 \\
\hline \multirow{5}{*}{ Reserva } & 5 & Linha 5 - BP 1305 & 98,50 \\
\cline { 2 - 4 } & 6 & Linha 6 - BP 1304 & 98,74 \\
\cline { 2 - 4 } & 7 & Linha 6 - BP 1304R & 95,43 \\
\cline { 2 - 4 } & 8 & Linha 7 - BP 2304 & 95,39 \\
\cline { 2 - 4 } & 9 & Linha 7 - BP 2304R & 97,94 \\
\cline { 2 - 4 } & 11 & Linha 8 - BP 3304 & 96,49 \\
\cline { 2 - 4 } & 12 & Linha 8 - BP 3304R & 99,15 \\
\cline { 2 - 4 } & 13 & Linha 9 - BP 2308 & 99,22 \\
\cline { 2 - 4 } & 14 & Linha 9 - BP 2308R & 98,44 \\
\hline
\end{tabular}

Verifica-se por meio da Tabela 2 que a DF das bombas de polpas varia entre $87,87 \%$ a $99,84 \%$. A partir dos dados apresentados na Tabela 2, desenvolveu-se o gráfico da Figura 2. 


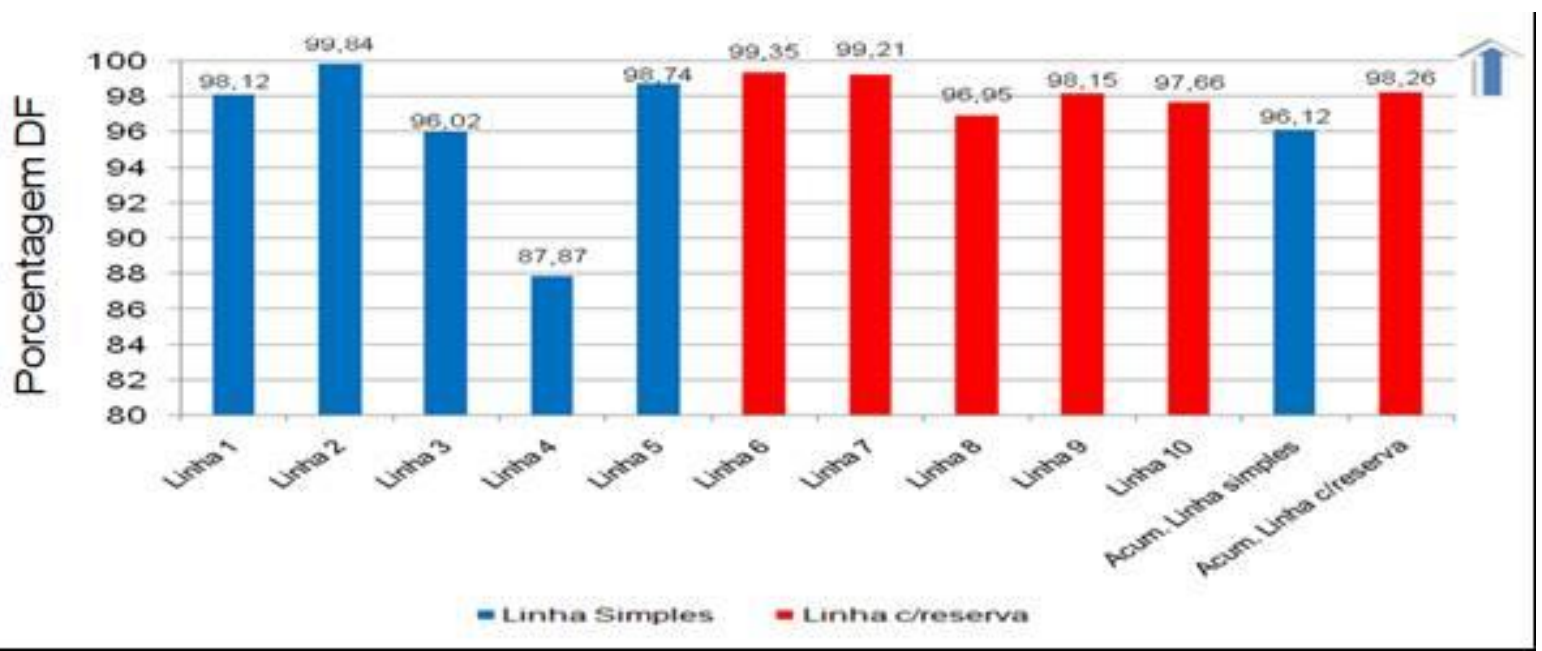

Figura 2 - Disponibilidade Física - Bombas de Polpas.

Por meio dos dados apresentados na Figura 2, pode-se afirmar que nas linhas de bombas em que são realizadas manutenções preventivas (linha simples), apresentaram DF menores que das linhas onde se realizam as manutenções corretivas (linha com reserva). Essa conclusão pode ser obtida a partir da comparação dos valores mostrados na coluna dos acumulados.

Uma análise mais criteriosa, observa-se que a Linha 4 apresentou um desempenho em DF abaixo da média dos demais. Considerando que nessa linha é realizada manutenção preventiva na bomba de polpa, foi verificado e constatado que esse problema ocorreu devido à falha no componente redutor do equipamento. Essa bomba de polpa encontrava-se em fase de testes do componente redutor, verificando que o eixo de entrada estava subdimensionado. Sendo assim, não foi capaz de suportar o torque aplicado, causando cisalhamento e falha do mesmo, levando a parada da Linha 4 por 48 horas, afetando a DF do equipamento.

Além do indicador DF, o setor de manutenção da empresa realizou um acompanhamento dos indicadores, do número de falhas, horas em operação, tempo médio entre falhas (MTBF) e tempos gastos para reparo (MTTR) das bombas de polpas. Os valores desses indicadores podem ser verificados na Tabela 3.

Tabela 3 - Indicadores: Número de Falhas; Horas de Operação; MTBF e MTTR.

\begin{tabular}{c|c|c|c|c}
\hline Linha e Bombas de Polpa & No de Falhas & $\begin{array}{c}\text { Horas em } \\
\text { Operação }\end{array}$ & MTBF (h) & MTTR(h) \\
\hline L1 - BP 1101 & 3 & $5.658,75$ & $1.886,25$ & 1,88 \\
\hline L2 - BP 1307 & 5 & $5.635,53$ & $1.127,11$ & 0,16 \\
\hline L3 - BP 1804 & 16 & $5.771,40$ & 360,71 & 3,98 \\
\hline L4 - BP 2307 & 36 & $5.577,86$ & 154,94 & 12,13 \\
\hline L5 - BP 1305 & 23 & $2.892,96$ & 125,78 & 1,26 \\
\hline L6 - BP 1304 / BP 1304R & 24 & $5.645,02$ & 235,21 & 1,50 \\
\hline L7 - BP 2304 / BP 2304R & 29 & $2.622,69$ & 90,44 & 4,57 \\
\hline L8-BP 3304 / BP 3304R & 48 & $3.393,39$ & 70,70 & 4,61 \\
\hline L9-BP 2308 / BP 2308R & 21 & $3.206,36$ & 152,68 & 2,06 \\
\hline L10-BP 4308/ BP 4308R & 48 & $4.033,55$ & 84,03 & 3,51 \\
\hline
\end{tabular}

Analisando a Tabela 3, nota-se que as bombas de polpa da Linha 8 são as que geraram o maior número de falhas em relação às horas em operação; a Linha 3 é superior as outras linhas sobre o tempo médio entre falhas (MTBF); a Linha 1 possui o menor número de falhas; a Linha 4 obteve o maior tempo médio para reparo (MTTR). 
Para melhor visualização desta análise, a Figura 3 apresenta o tempo de operação das linhas, além do índice acumulado, para melhor comparação.

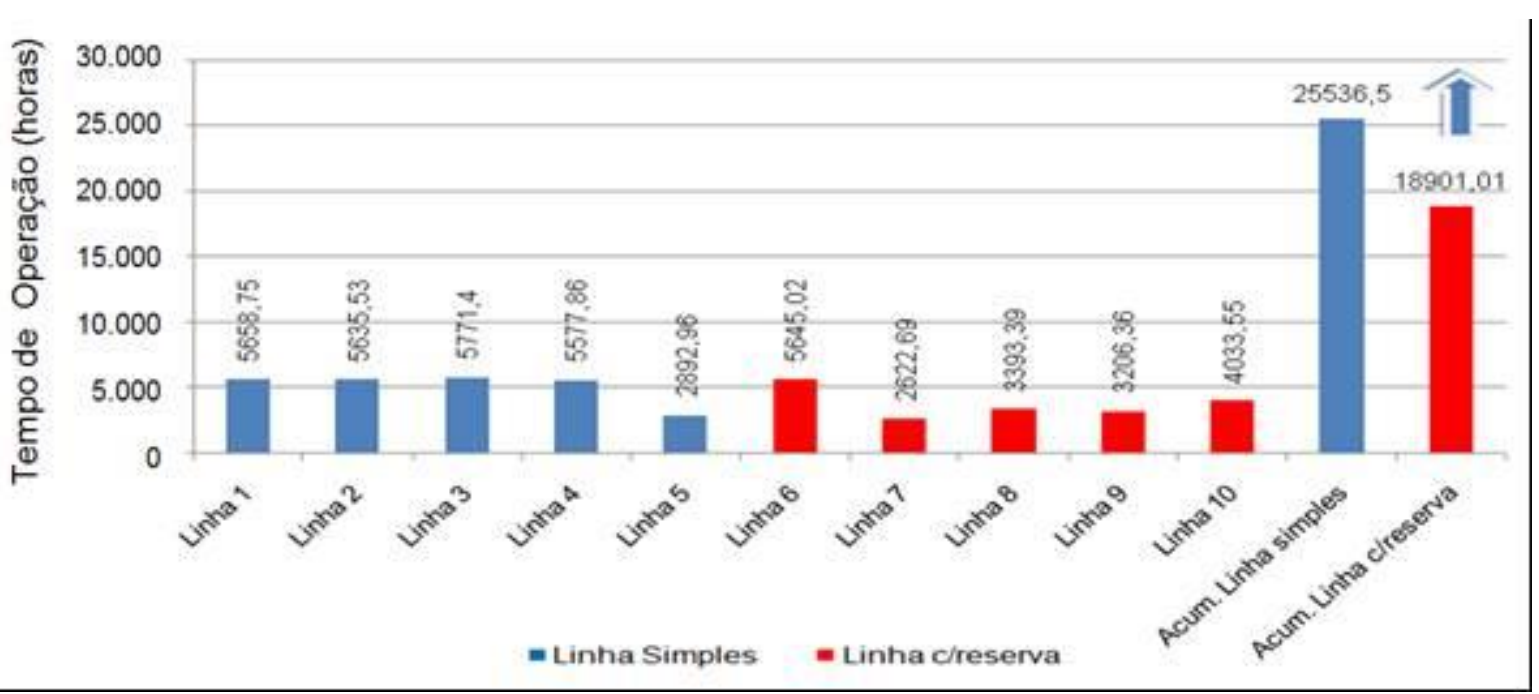

Figura 3 - Horas em Operação - Bomba de polpa.

Ao analisar a Figura 3, foi identificado que as linhas onde se adotam a manutenção preventiva apresentaram maior tempo de operação, cerca de $35 \%$ de horas a mais se comparadas às linhas com estratégia de manutenção corretiva.

No que diz respeito ao número de falhas das linhas onde se encontram as bombas de polpa, uma análise foi realizada a partir dos dados apresentados na Figura 4.

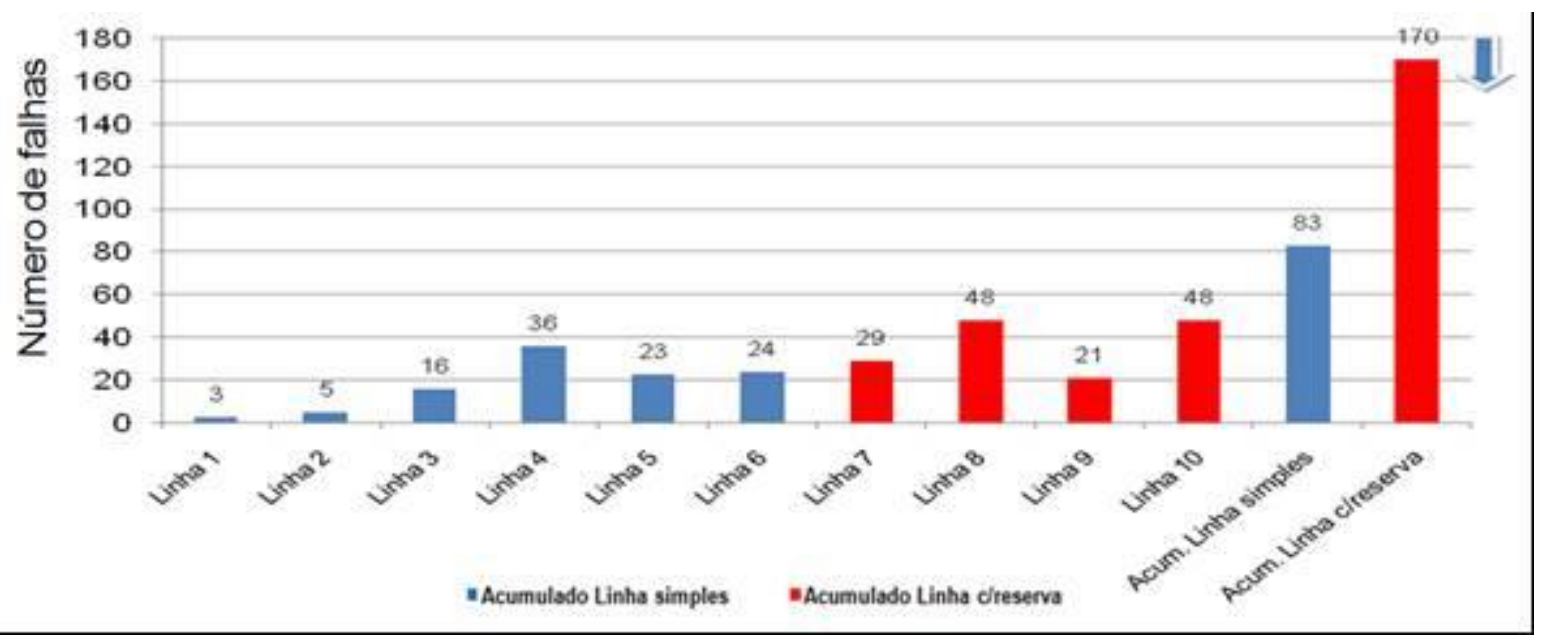

Figura 4 - Número de Falhas - Bombas de Polpa.

Observa-se que nas linhas onde se adotam a manutenção corretiva o número de falhas foi maior, o que significa que se o equipamento não tem uma manutenção preventiva as falhas são inerentes ao processo. Aproximadamente $105 \%$ mais falhas que nas linhas onde se adotam a manutenção preventiva.

A análise dos gráficos das Figuras 3 e 4 revelaram que, mesmo apresentando um tempo de operação maior, os equipamentos das linhas onde se adotam a manutenção preventiva tendem a falhar menos. Com isso, notou-se um desempenho consideravelmente melhor no indicador tempo médio entre falhas (MTBF), conforme mostra a Figura 5. 


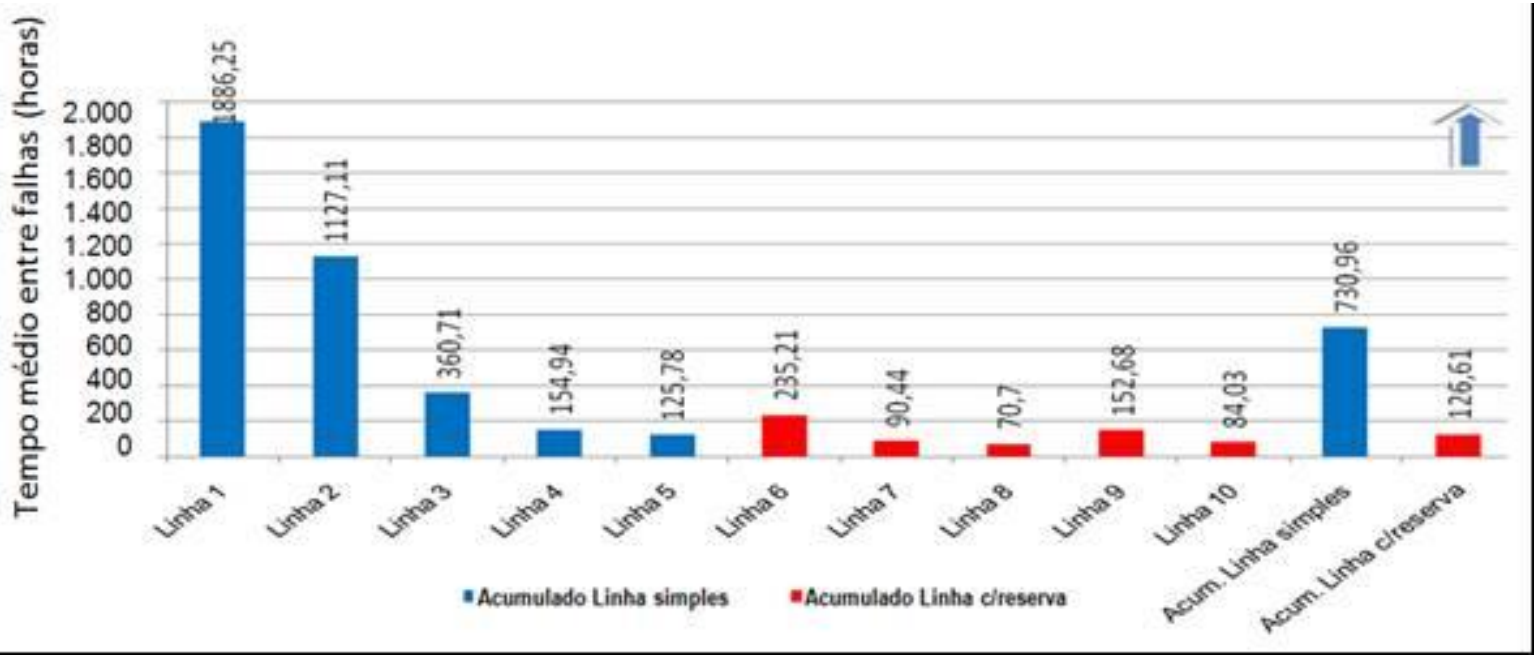

Figura 5 - Tempo médio entre falhas (MTBF) - Bombas de Polpa.

Através da Figura 5, identificou-se que, em média, nas linhas onde se adotam manutenção preventiva, os equipamentos apresentaram falha a cada 730 horas, enquanto que nas linhas onde se adotam a manutenção corretiva ocorrem falham a cada 126 horas.

O tempo médio para reparo (MTTR) foi analisado e seu desempenho está apresentado na Figura 6.

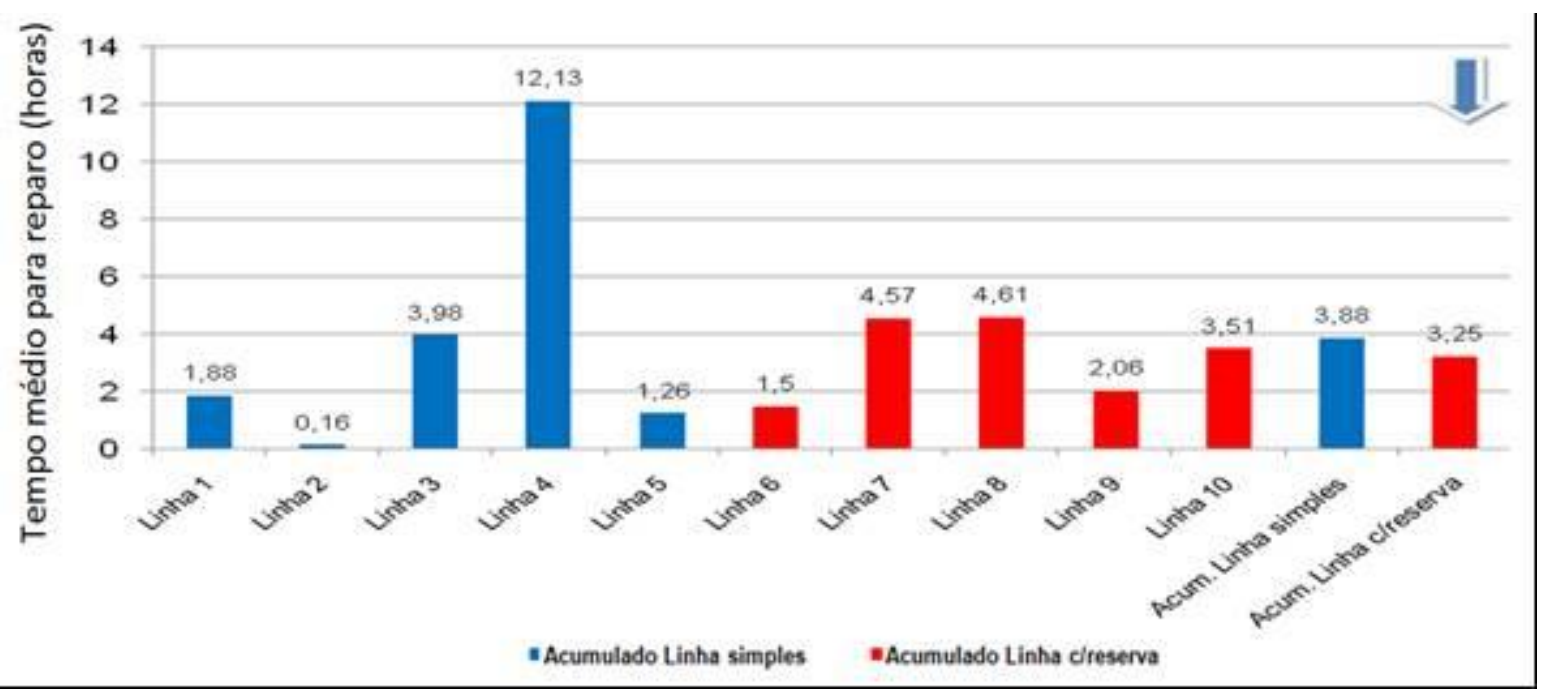

Figura 6 - Tempo médio para reparo (MTTR) - Bombas de Polpa.

Verifica-se através da Figura 6 que, em média, o tempo gasto para reparo nas linhas onde se atua preventivamente é maior que nas linhas que ocorrem a manutenção corretiva. Ressalta-se novamente que a Linha 4 impactou negativamente o indicador MTTR devido a falha na bomba de polpa dessa linha conforme explicado anteriormente.

Por último, foi realizada uma análise dos custos das linhas com aquisição de peças e equipamentos reservas, conforme se pode verificar na Tabela 4. 
Tabela 4 - Custo - Bomba de Polpa $(R \$)$.

\begin{tabular}{c|c|c}
\hline Linha & Peças & Equipamento Reserva \\
\hline Linha 1 & $19.611,95$ & - \\
\hline Linha 2 & $13.107,46$ & - \\
\hline Linha 3 & $28.006,34$ & - \\
\hline Linha 4 & $13.107,46$ & - \\
\hline Linha 5 & $8.504,29$ & - \\
\hline Linha 6 & $27.803,82$ & $22.597,75$ \\
\hline Linha 7 & $41.109,01$ & $125.666,17$ \\
\hline Linha 8 & $125.780,04$ & $35.091,49$ \\
\hline Linha 9 & $28.542,84$ & $12.566,17$ \\
\hline Linha 10 & $146.116,44$ & $125.474,98$ \\
\hline
\end{tabular}

A partir da Tabela 4, observa-se que a Linha 10 foi a que teve um maior gasto com peças e as Linhas 7 e $10 \mathrm{com}$ equipamento reserva. Esta relação de custo é apresentada nas Figuras 7 e 8 , custo para a empresa no período de janeiro a setembro de 2016.

A Figura 7 apresenta 0 custo de manutenção total com peças e equipamentos reservas por linha.

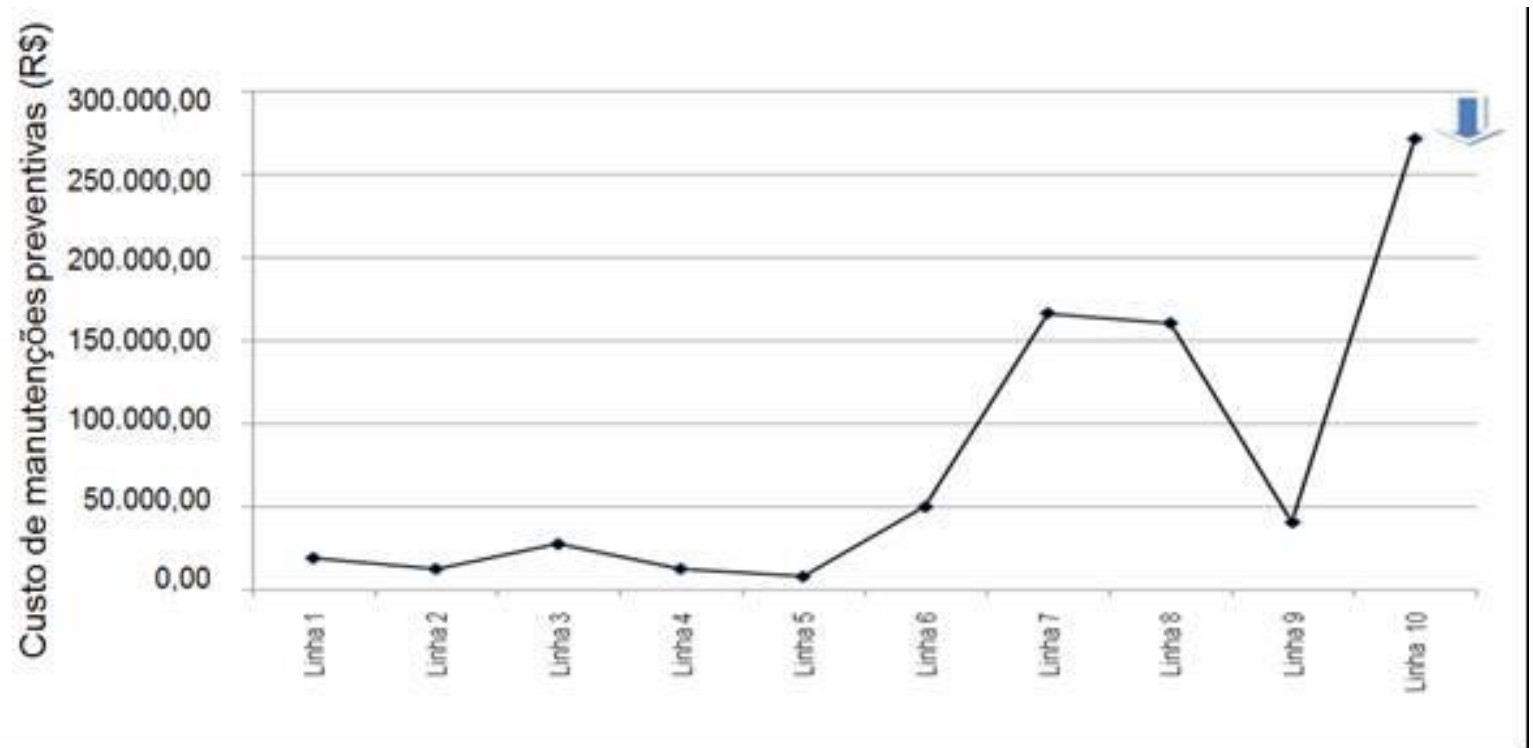

Figura 7 - Custo $(\mathrm{R} \$)$ - Bombas de Polpa.

Observa-se através da Figura 7 que a empresa teve maior custo com a manutenção da Linha 10. Além disso, a pesquisa identificou que as linhas onde se atua com manutenções corretivas apresentaram maior custo para a empresa.

No que se refere aos custos, a Figura 8 apresenta o valor acumulado e médio dos gastos com as linhas simples, onde são realizadas manutenções preventivas, e com as linhas com equipamentos reservas, manutenções corretivas. 


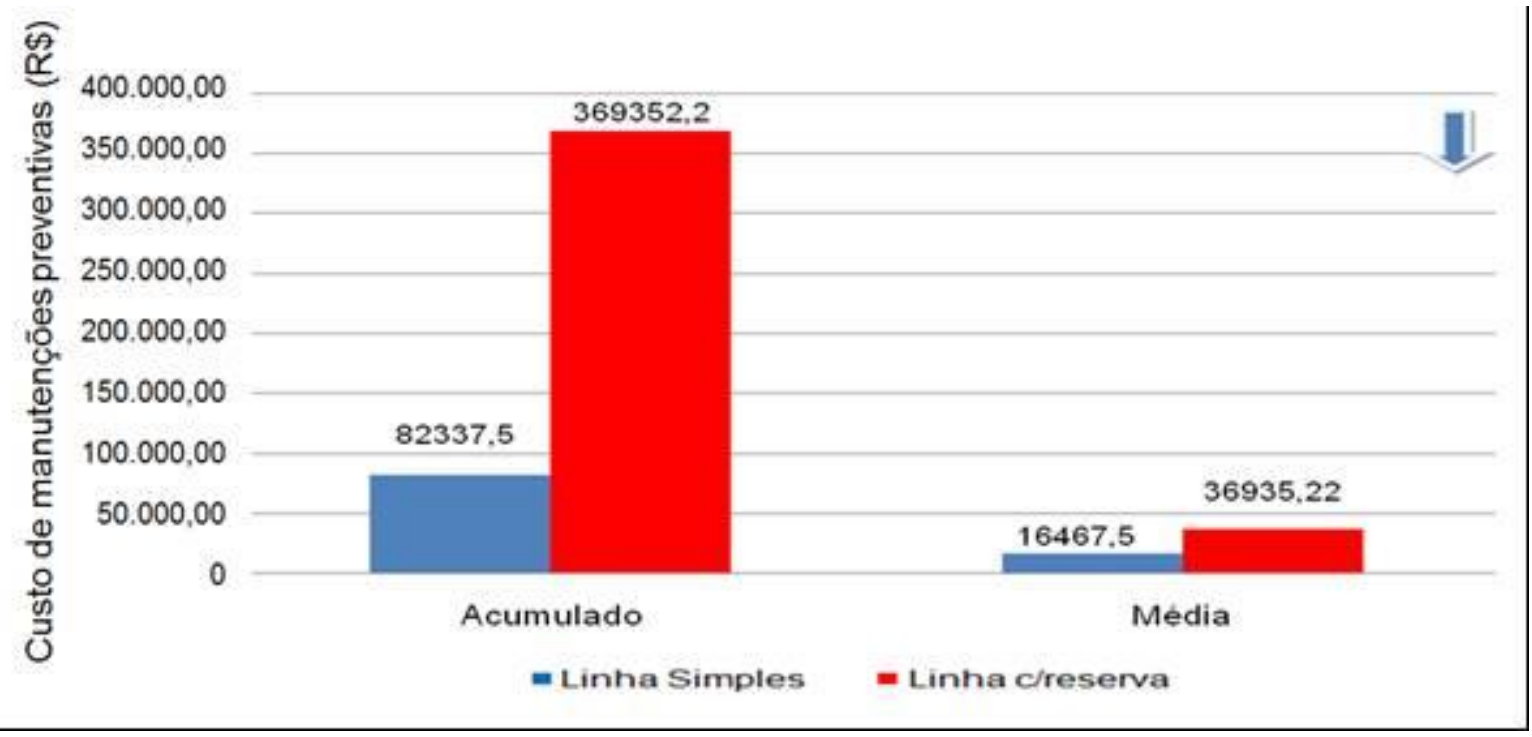

Figura 8 - Comparativo Custo.

Como se observou na Figura 8, gastos com manutenções corretivas nas bombas de polpa são cerca de $350 \%$ maiores se comparadas às manutenções preventivas. Foi identificado no estudo que, em média, cada equipamento das linhas onde se adota a manutenção corretiva custou cerca de $124 \%$ a mais que os equipamentos das linhas onde se adota manutenção preventiva.

\section{CONCLUSÕES}

O presente estudo teve como objetivo verificar qual tipo de manutenção em bomba de polpa é o mais indicado no processo de beneficiamento de minério de ferro.

Por meio da proposta, analisou-se o desempenho dos equipamentos nos indicadores de manutenção de acordo com a estratégia de manutenção adotada.

Após análise dos dados coletados, levando-se em consideração os indicadores de manutenção no período analisado, de janeiro a setembro de 2016, notou-se que, apesar das linhas onde se realiza a manutenção corretiva, apresentarem melhores índices de disponibilidade física e no tempo médio para reparos (MTTR), isso não representou bons índices nos outros indicadores analisados: horas em operação, número de falhas, tempo médio entre falhas (MTBF) e custo.

Concluiu-se que não se pode avaliar o desempenho de uma estratégia de manutenção levando-se em consideração apenas um indicador isoladamente, pois todos indicadores estão correlacionados entre si, e uma análise individual pode levar a conclusões equivocadas.

Nesse sentido, o estudo possibilitou mostrar que a manutenção corretiva apresentou menor confiabilidade que a manutenção preventiva, pois teve maior número de falhas, o que representou também maior custo para a empresa estudada.

Kardec et $\mathrm{al}^{4}$ ressaltam a importância da manutenção como função estratégica para melhoria dos resultados e aumento da competitividade das empresas no mercado. Ao levar em consideração essa citação dos autores, nos dias atuais, as empresas consideram a redução de custos de suas operações como um diferencial competitivo. A análise dos indicadores evidenciou que quanto menos se adotar a manutenção corretiva, melhor será para a empresa se manter forte no mercado, pois terá sua capacidade produtiva garantida e aumentado a confiabilidade de seus processos e equipamentos com menores custos. 


\section{REFERÊNCIAS}

1 FRANCIA, L. China continuará a derrubar o preço do minério de fero: política chinesa causou redução do consumo global e retraiu a demanda pelo insumo siderúrgico. Diário do Comércio. 2016. Disponível em: http://www.diariodocomercio.net.br/noticia.php?tit=china_continuara_a_derrubar o_preco_do_minerio_de_ferro\&id=164789. Acesso em: 30/04/2017.

2 ROCHA, Felipe Augusto Tetzl. Bombeamento de polpa e o fator de atrito. 2010. 40f. Monografia (Pós-Graduação em Engenharia de Minas) - Universidade Federal de Ouro Preto, Ouro Preto, 2010.

3 SILVA, Vera Dimar. Bombas Centrífugas de Polpa. 2011. 60f. Monografia (PósGraduação em Engenharia de Recursos Minerais) - Escola de Engenharia, Universidade Federal de Minas Gerais, Belo Horizonte, 2011.

4 KARDEC, Alan; NASCIF, Júlio. Manutenção: Função Estratégica. 3.ed. Rio de Janeiro: Qualitymark: Petrobrás, 2009.

5 SANTANA, Rodrigo Silva; SOUZA, Manuela Soares. A importância do planejamento e controle da manutenção: um estudo de caso na indústria Alfa de bebidas. Revista eletrônica da Faculdade José Augusto Vieira, Cidade Nova. n. 9 7, ano 5, set. 2012. Disponível em: www.fjav.com.br/.../A_importancia_do_planejamento_e_controle. Acesso em: 24. abr. 2016.

6 OLIVEIRA, Davi Borges. Manutenção preditiva com ênfase em termografia: um estudo de caso em um indústria sucroalcooleira. 2012, 36f. Monografia (Bacharel em Engenharia de Produção) - Centro Universitário De Formiga UNIFOR, Formiga, 2012.

7 KACH Cesar Simei; FELDEN, Catia Raquel. Gestão de sistema de manutenção com utilização das inovações tecnológicas. In: SEMANA INTERNACIONAL DAS ENGENHARIAS DA FAHOR, 4를, 2014 , Horizontina. Anais. Horizontina, SIEF, 2014.

8 FILHO, Gil. Branco. Indicadores e Índices de Manutenção. 1ed. Rio de Janeiro: Ciência Moderna, 2006.

9 NETTO, C. Wady Abrahão. A importância e a aplicabilidade da manutenção produtiva total (TPM) nas indústrias. 2008. 53 f. Trabalho de conclusão de curso (Graduação em Engenharia de Produção) - Universidade Federal de Juiz de Fora, Juiz de Fora, 2008. 